\title{
Comparative study of titrated oral misoprostol solution and vaginal dinoprostone for labor induction at term pregnancy
}

\author{
Xiu Wang ${ }^{1}$ Aijun Yang ${ }^{1}$ Qingyong $\mathrm{Ma}^{2} \cdot$ Xuelan $\mathrm{Li}^{3} \cdot$ \\ $\mathrm{Li} \mathrm{Qin}^{4} \cdot$ Tongqiang $\mathrm{He}^{5}$
}

Received: 19 August 2015/Accepted: 18 December 2015/Published online: 8 January 2016

(C) The Author(s) 2015. This article is published with open access at Springerlink.com

\begin{abstract}
Objective To evaluate effectiveness and safety of titrated oral misoprostol solution (OMS) in comparison with vaginal dinoprostone for cervix ripening and labor induction in term pregnant women.

Methods A multicenter randomized controlled trial of women with term singleton pregnancy with indications for labor induction; 481 participants were allocated to receive titrated OMS with different doses by hourly administration according to the procedure or insert vaginal dinoprostone for cervix ripening and labor induction to compare maternal outcomes including indication of labor induction, mode of outcome of delivery, maternal morbidity, and neonatal outcomes between two groups for evaluating the efficacy and safety of titrated oral misoprostol induction.

Result Proportion of delivery within $12 \mathrm{~h}$ of titrated oral misoprostol is significantly less than vaginal dinoprostone
\end{abstract}

Xiu Wang

3137119239@qq.com

Aijun Yang

2640933799@qq.com

Qingyong Ma

qyma56@mail.xjtu.edu.cn

Xuelan Li

lixuelan1225@126.com

Li Qin

qinqin2176@126.com

Tongqiang He

qinyu323@163.com

1 Department of Gynecology and Obstetrics, Affiliated Guangren Hospital of Xi' an Jiaotong University, No. 21, Jiefang Road, Xi' an 710004, Shaanxi, China
( $p=0.03$ ), but no difference of total vaginal delivery rate $(p=0.93)$; the mean time of first treatment to vaginal delivery was longer in OMS group $(21.3 \pm 14.5 \mathrm{~h})$ compared with the vaginal dinoprostone group $(15.7 \pm 9.6 \mathrm{~h})$. Although the proportion of cesarean section between the two groups showed no statistically significant difference, OMS group showed significantly lower frequency of uterine hyperstimulation, hypertonus, partus precipitatus and non-reassuring fetal heart rate than dinoprostone group. Neonatal outcomes were similar evaluating from Apgar score and NICU admission. Our study also showed that labor induction of women with cervix Bishop score $\leq 3$ needed increased dosage of misoprostol solution.

Conclusion Titrated OMS is as effective as vaginal dinoprostone in labor induction for term pregnant women, with safer effect for its lower rate of adverse effect for women.
2 Department of Hepatobiliary Surgery, First Affiliated Hospital of Medical College, Xi'an Jiaotong University, No. 61, Jiankang Road, Xi'an 710061, Shaanxi, China

3 Department of Gynecology and Obstetrics, First Affiliated Hospital of Medical College, Xi' an Jiaotong University, No. 61, Jiankang Road, Xi'an 710061, Shaanxi, China

4 Obstetric Department of Shannxi Province People Hospital, No. 42, Friendship Road, Xi'an 710068, Shaanxi, China

5 Obstetric Department of Maternal and Child Care Service Center of Northwest, No. 1616, Yanxiang Road, Xi'an 710008, Shaanxi, China 
Keywords Titrated oral misoprostol - Labor induction . Dinoprostone $\cdot$ Efficacy and safety

\section{Background}

Induction of labor is a commonly practiced obstetric intervention designed to artificially initiate the process of effacement of cervix, dilatation and eventually delivery of baby. Adopting safe and effective methods of labor induction at appropriate gestation age can greatly decrease complications and morbidity of pregnancy and fetus. In recent years, the rate of induction presents gradually increasing tendency, and the incidence for labor induction dramatically varies $8-44 \%$ [1-3]. Therefore, looking for induction methods with safety, efficacy, feasibility, low cost, and patient preferences, for a long time, is a pursuit of the goal of all obstetric providers.

Recently, many studies reported oral misoprostol for labor induction with different doses and interval times; at the same time, respectively compared with other induction methods including vaginal insert misoprostol, oxytocin, Foley catheter induction, oxytocin associated Foley catheter and vaginal insert Dinoprostone. The target of all these studies is to evaluate the safety and effectiveness of oral misoprostol for labor induction. According to these study results, we propose the concept that misoprostol will be a new promising agent for cervical ripening and induction of labor, but ideal dose, route and administration frequency are still needed for investigation.

Misoprostol, a synthetic prostaglandin $\mathrm{E}_{1}$ analog, can be administered orally, sublingually, buccally, intra-vaginally, or rectally and is used for both cervical ripening and labor induction. The World Health Organization recommends a fixed oral misoprostol dose of $25 \mathrm{mg}$ every $2 \mathrm{~h}$ for labor induction based on moderate-quality evidence and strong recommendation [4]. However, trials continue in efforts to identify the optimum treatment regimen.

On the basis of the misoprostol pharmacokinetics, this medicine shows the characteristics of rapid oral absorption, its active metabolites of misoprostol acid in plasma reach peak value after $15 \mathrm{~min}$ of oral administration, and its mean tmax concentration is $0.309 \mu \mathrm{g} / \mathrm{L}$. Its half-life is 20-40 min following oral administration, followed by a rapid decline to low levels during the period of $120 \mathrm{~min}$, thereafter with a more gradual decline, and no drug accumulation phenomenon. According to its pharmacokinetics property, we designed the administration procedure of hourly titrated oral misoprostol dosing and gradually increasing dosage, compared with $2 \mathrm{~h}$ dosing; this procedure may make drug serum level more steady with better efficacy, and at last improve clinical induction outcome.

\section{Materials and methods}

\section{Design}

This trial was a multicenter, open-label, randomized controlled trial. The study was performed within four obstetric centers; participating hospitals can be district, teaching or academic hospitals. Before entry into the study, women were informed about the aims, methods, reasonably anticipated benefits and potential hazards of the study. Prior to interview, informed consents had been taken from every respondent. Patients who met the selection criteria were explained about advantages and disadvantages of the procedure. Among them, those who provided their informed consents were interviewed and recruited in the study. They were informed that their participation would been voluntary and may withdraw consent for participation at any time during the study.

\section{Inclusion criteria}

All the women must be singleton pregnancies with occipital presentation, nullipara, gestational age is at least 36 weeks, Bishop score less than six, no vaginal delivery contraindication, e.g. cephalopelvic disproportion, mal-presentation, fetal compromise, no reassuring fetal heart rate pattern, previous scar and antepartum haemorrhage.

\section{Exclusion criteria}

Women with any contraindication to induction and vagina delivery, allergic to prostaglandin, and with complication of glaucoma, asthma and allergic colitis, woman with heart, liver, renal and adrenal cortex insufficiency.

\section{Multicenter randomized control design}

This multicenter randomized controlled trial was conducted from January to October in 2014 at four gynecologic and obstetric departments (including Obstetric Department of Affiliated Guangren Hospital of Xi'an Jiaotong University; Obstetric Department of First Affiliated Hospital of Medical College of Xi'an Jiaotong University in China; Obstetric Department of Maternal and Child Care Service Center of Northwest; Obstetric Department of Shannxi Province People Hospital). On enrollment, an opaque envelope corresponding to the participant's enrollment number was opened assigning women to either oral misoprostol or vaginal insert dinoprostone group determined by a computer-generated randomization sequence. 


\section{Methods of administration and evaluation}

Based on the WHO labor induction recommendation, and for the purpose of achieving precise oral misoprostol dosage, we pulverized one misoprostol tablet $(200 \mu \mathrm{g})$, dissolved into $200 \mathrm{ml}$ water, then one misoprostol tablet $(200 \mu \mathrm{g})$ was made into $1 \mu \mathrm{g} / \mathrm{ml}$ concentration oral misoprostol solution (OMS), and preserved at room temperature for $24 \mathrm{~h}$.

All the women enrolled into OMS group were given misoprostol solution according to the procedure (Fig. 1) and ceased procedure at any time when reached one of the following criteria: including regular uterine contractions every 3-5 min and lasting $60 \mathrm{~s}$ or more; dilatation of cervix reached $2.0 \mathrm{~cm}$; emerging membrane rupture; uterine tachysystole; uterine hyperstimulation as tachysystolic, non-reassuring fetal heart rate. The whole procedure spent $10.5 \mathrm{~h}$, when woman ends the first procedure with no signs of regular uterine contraction, after $6 \mathrm{~h}$ interval, we would begun second cycles procedure, in second procedure, the criteria of ceasing procedure is as same as previous norms.

The vaginal insert dinoprostone was given according to the drug protocol. Dinoprostone should be removed from the freezer in direct connection with the insertion, and be inserted high into the posterior vaginal fornix using only small amount of water soluble lubricants to aid insertion. After dinoprostone has been inserted, the withdrawal tap may be cut with scissors ensuring there is sufficient tap outside the vagina to allow removal. The norms of terminating drug administration were as same as OMS group.

When participants began the process of labor induction, abdominal palpation uterine contraction and electric monitoring would be taken to evaluate uterine contraction, fetal heart-rate every hour, and vaginal exam to know the dilatation of cervix every $1-2 \mathrm{~h}$.

\section{Outcomes measure}

General situation of participants: including age, gestational age, body mass index (BMI). Indication of labor induction: premature rupture of membrane (PROM), oligohydramnios, post-term gestation, pre-eclampsia, gestational diabetes mellitus (GDM) controlled without insulin, and other reasons. Mode and outcome of delivery: including mode of delivery such as spontaneous delivery, vaginal operative delivery or cesarean section, and the reason for operative delivery and cesarean section; Induction to delivery time: less than $12 \mathrm{~h}$ delivery, $12-24 \mathrm{~h}$ delivery and $24-48 \mathrm{~h}$ delivery; Cervix Bishop score; total oral misoprostol dosage; oxytocin use situation; requirement of analgetics; pertus precipitatus (defined as the total time of labor stage less than $3 \mathrm{~h}$ ); reasons of cesarean section and operative delivery. Maternal morbidity: postpartum blood transfusion and number of packed cell, Tachysystole (defined as more than five contractions in $10 \mathrm{~min}$ ); hyperstimulation (defined as tachysystole with FHR changes); uterine hypertonus (defined as a contraction lasting longer than $2 \mathrm{~min}$ with FHR changes); Uterine rupture (occurrence of clinical symptoms include abdominal pain, abnormal fetal heart rate pattern, acute loss of contractions and vaginal blood loss) leading to an emergency cesarean delivery, at which the presumed diagnosis of uterine rupture was confirmed; or peripartum hysterectomy or laparotomy for uterine rupture after vaginal birth); Maternal infection during labor (defined as fever, i.e. temperature $\geq 37.8^{\circ} \mathrm{C}$, or fetal tachycardia and start of antibiotics); maternal infection within 1 week postpartum (defined as fever, i.e. temperature $\geq 37.8^{\circ} \mathrm{C}$, and start of antibiotics); start of intravenous antibiotics; endo (myo)metritis or urinary tract infection within 1 week postpartum (proven positive vaginal/urine culture); other medication used during labor such as tocolytics. Neonatal parameters consisting of: fetal tachycardia (sustained fetal heart rate above 160 beats per minute), fetal distress; weight at birth; meconium-stained liquor; Apgar scores $<7$ at 1, 5, and $10 \mathrm{~min}$; admission to the neonatal ward/NICU and its reason (suspected infection, infection proven by positive culture, other reason admission to medium or intensive care).

\section{Statistical analysis}

All data were analyzed by statistics software SPSS 19.0. Results were given as mean \pm SD or percentage, time intervals were analyzed with ANOVA test, other data were analyzed with $\chi^{2}$ for qualitative and Student's $t$ test for quantitative variables. All tests were two-sided, $p<0.05$ was considered statistically significant.

\section{Results}

A total of 481 women met the inclusion criteria and approached regarding study participation, 35 women declined, of whom 228 women were randomized to OMS group and 218 women to vaginal dinoprostone group. 35 participants did not receive the assigned drug, 16 women in the OMS group and 19 women in vaginal dinoprostone group. Reasons for not receiving the study drug mainly included the following causes: initiating spontaneous regular uterine contraction, non-reassuring FHR, and refusal of study drug (Fig. 2).

There were no differences in maternal age, gestational age and body weight index between OMS and vagina dinoprostone groups (Table 1). We also compared the labor induction indication between two groups, showed no difference of indication in oligohydramnios, posterm 


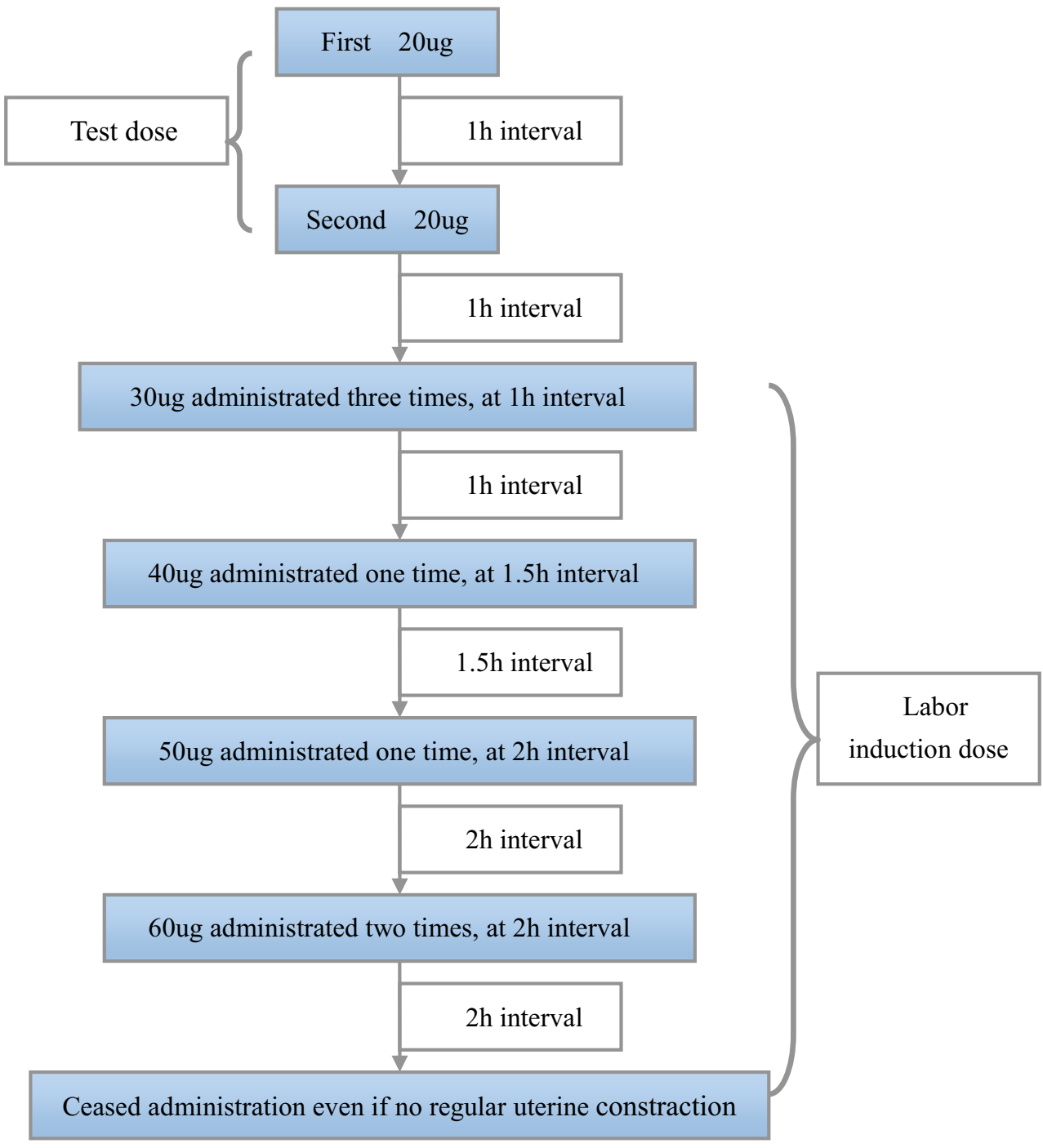

Note: ceased procedure at any time when reached one criteria of following norm, including regular uterine contractions every 3-5 minutes and lasting 60 seconds or more; dilatation of cervix reached $2.0 \mathrm{~cm}$; emerging membrane rupture, uterine tachysystole, uterine hyperstimulation as tachysystolic, non-reassuring fetal heart rate.

Uterine tachysystole was defined as more than 5 contractions in a 10 minute period without fetal heart rate changes and uterine hyperstimulation as tachysystolic uterine contractions associated with non-reassuring fetal heart rate pattern. Non-reassuring fetal heart rate was defined as an abnormal fetal heart rate on electronic monitoring such as more than three continuous late deceleration, frequent emerging serious variable deceleration.

Fig. 1 Flow diagram of process of hourly adminstration titrated oral misoprostol solution and ceased procedure criteria 


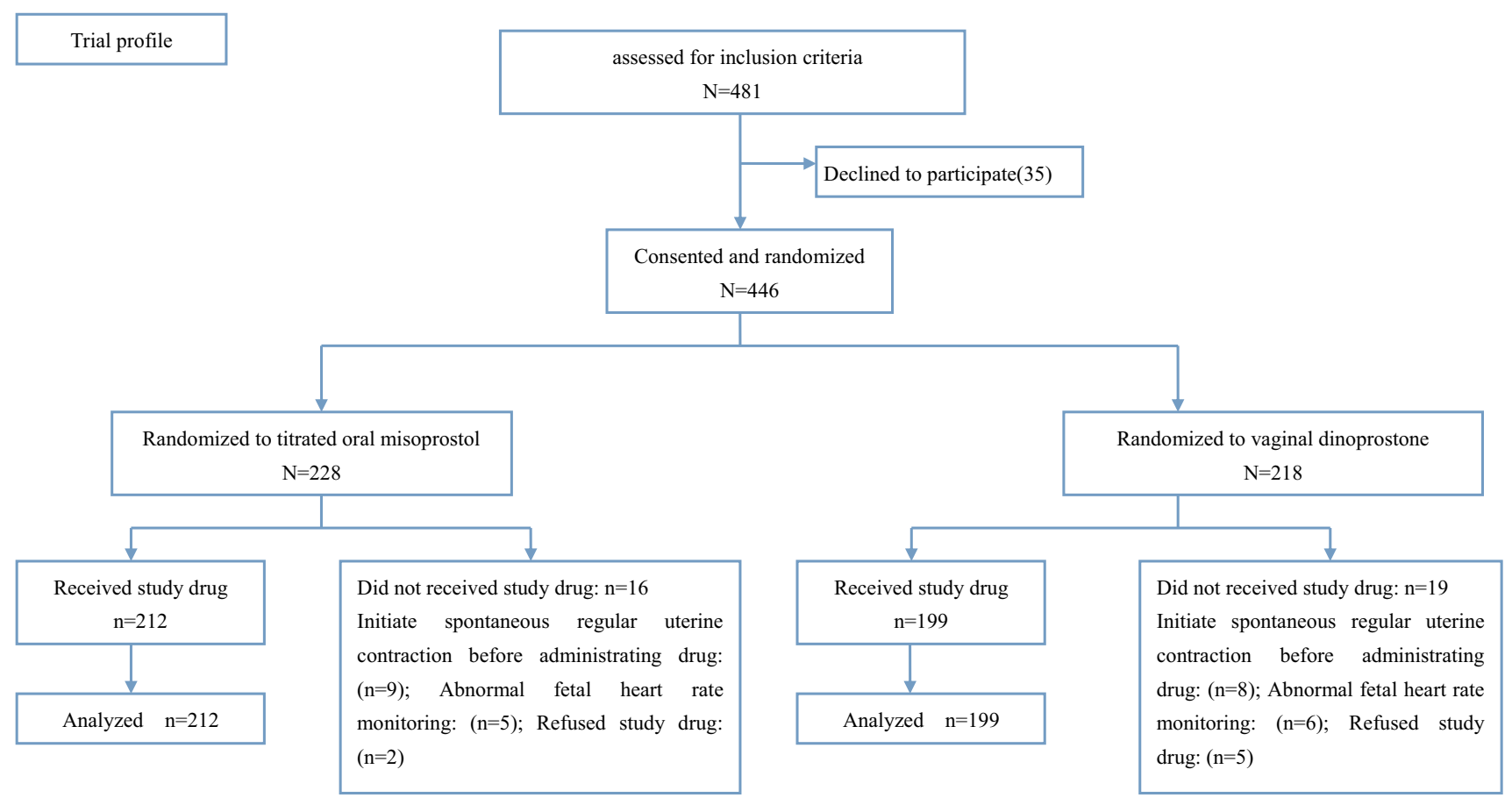

Fig. 2 Procedures for the selection and follow-up of participants

Table 1 General condition of study participants

\begin{tabular}{llll}
\hline & Oral misoprostol $(n=212)$ & Dinoprostone $(n=199)$ & $p$ value \\
\hline Maternal age (years) & $27.8 \pm 4.8(18-39)$ & $28.3 \pm 5.6(18-35)$ & 0.84 \\
Gestational age (weeks) & $39.5 \pm 6.2(36-42)$ & $38.8 \pm 7.1(36-42)$ & 0.98 \\
BMI $\left(\mathrm{Kg} / \mathrm{m}^{2}\right)$ & $25.3 \pm 8.7(18.9-33.5)$ & $26.1 \pm 8.2(18.5-32.8)$ & 0.89 \\
\hline
\end{tabular}

Data are mean \pm SD (range)

$B M I$ body mass index

\begin{tabular}{lccc}
\hline & Oral misoprostol $(n=212)$ & Dinoprostone $(n=199)$ & $p$ value \\
\hline Oligohydramnios & $127(56.9)$ & $117(58.7)$ & 0.92 \\
Post term-gestation & $32(15.1)$ & $36(18.0)$ & 0.87 \\
GDM & $13(6.1)$ & $11(5.5)$ & 0.72 \\
PROM & $19(8.9)$ & $15(7.5)$ & 0.82 \\
Pre-eclampsia & $12(5.6)$ & $10(5.0)$ & 0.90 \\
FGR & $6(2.8)$ & $6(3.0)$ & 0.91 \\
Other & $3(1.4)$ & $4(2.0)$ & 0.73 \\
\hline
\end{tabular}

Data are number (percentage)

GDM gestational diabetes mellitus, PROM premature rupture of membrane, FGR fetal growth restriction
Table 2 Indication of labor induction interval of time, within $12 \mathrm{~h}$ the proportion of vaginal delivery in OMS was lower than dinoprostone group with significant difference $(p=0.03)$, but during $24-48 \mathrm{~h}$ the percentage of vaginal delivery was obviously higher than dinoprostone $(p=0.04)$, and during $12-24 \mathrm{~h}$ delivery proportion was similar between two groups $(p=0.89)$; 
however, the mean time of first treatment to vaginal delivery was significantly longer in OMS group $(21.3 \pm 14.5 \mathrm{~h})$ compared with the vaginal dinoprostone group $(15.7 \pm 9.6 \mathrm{~h})$. Proportion of cesarean section in vaginal dinoprostone $(36 / 199,18.0 \%)$ was a little higher than OMS $(30 / 212,14.2 \%)$, but statistically no significance, analyzing the indication of cesarean section, the dinoprostone group showed higher fetal distress, but the difference without statistically significant, and proportions of delivery process block were similar between groups. The proportion of total vaginal operative delivery showed no significant difference between the two groups, and causes of vaginal operative delivery (forceps and vacuum extractor delivery) mainly include uterine atony, fetal distress and delivery process block, proportion of three main causes of vaginal operative delivery were similar. Compared other respects include using oxytocin and requirement of analgetics showed no difference between groups. Proportion of partus precipitatus in vaginal dinoprostone $(9 / 163,5.5 \%)$ was higher than oral misoprostol $(5 / 182,2.7 \%$ ) (Table 3$)$.

Based on women cervix Bishop score, we divided into two subgroups, respectively, $\leq 3$ and $4-6$. We found that proportions of successful induction were similar between groups, however, Bishop score less than 3 or $4-6$, but women with Bishop score $\leq 3$ in oral misoprostol group administered more misoprostol solution dose. The mean dosage of oral misoprostol solution is $180 \pm 120 \mu \mathrm{g}$, and further stratified by cervix Bishop score, the mean dosage of misoprostol $435 \pm 124 \mu \mathrm{g}$ in the Bishop score $\leq 3$, and $152 \pm 95 \mu \mathrm{g}$ in the Bishop score 4-6 subgroup. Duration time of first treatment to vaginal delivery was longer than Bishop score 4-6 subgroup; 51 women gave birth during 24-48 h. We also compared the frequency of maternal adverse events between groups, the overall uterine tachysystole was not different between the two groups; 18 women in vaginal dinoprostone group had hyperstimulation, its frequency is significantly higher than oral misoprostol group ( $p=0.03$ ). Five women in oral misoprostol and 16 women in vaginal dinoprostone presented uterine hypertonus with significantly difference $(p=0.03)$. 6 women in OMS and 17 in dinoprostone group needed tocolytics to inhibit uterine hyperstimulation, tachysystole and hypertonus, the result showed significantly difference $(p=0.04)$. The proportion of membrane rupture phenomenon in OMS $(59 / 212,27.8 \%)$ is higher than vaginal dinoprostone $(26 / 199,13.1 \%)$. Proportion of postpartum heamorrhage and intravenous antibiotics was similar between the groups, and maternal other adverse event including fever, shivering, nausea and vomiting also present no difference (Table 4).

Neonatal outcomes are shown in Table 5, neonatal Apgar scores $\leq 7$ at the interval of 1, 5 and 10 min were no different, and the proportions of Meconium-stained liquor and neonate NICU admission were also similar, but non-
Table 3 Mode and outcome of delivery

\begin{tabular}{llll}
\hline & $\begin{array}{l}\text { Oral misoprostol } \\
(n=212)\end{array}$ & $\begin{array}{l}\text { Dinoprostone } \\
(n=199)\end{array}$ & $p$ value \\
\hline Delivered vaginally & $182 / 212(85.8)$ & $163 / 199(81.9)$ & 0.93 \\
$<12 \mathrm{~h}$ & $39 / 182(21.4)$ & $65 / 163(40.1)$ & 0.03 \\
During 12-24 h & $79 / 182(43.4)$ & $66 / 163(40.4)$ & 0.89 \\
During 24-48 h & $58 / 182(31.9)$ & $28 / 163(17.2)$ & 0.04 \\
First treatment to vaginal delivery, & $21.3 \pm 14.5$ & $15.7 \pm 9.6$ & 0.04 \\
$\quad$ mean $h$ & & & \\
Bishop score & & $57 / 163(34.9)$ & 0.32 \\
$\leq 3$ & $69 / 182(37.9)$ & $106 / 163(65.0)$ & 0.78 \\
$4-6$ & $113 / 182(62.1)$ & $36 / 199(18.0)$ & 0.34 \\
Cesarean section & $30 / 212(14.2)$ & $10 / 36(27.8)$ & 0.44 \\
Fetal distress & $7 / 30(23.3)$ & $26 / 36(72.2)$ & 0.86 \\
$\quad$ Delivery process block & $23 / 30(76.7)$ & $29 / 163(17.8)$ & 0.50 \\
Vaginal operative delivery & $22 / 182(12.1)$ & $9 / 29(31.0)$ & 0.80 \\
Uterine atony & $8 / 22(36.4)$ & $12 / 29(41.4)$ & 0.79 \\
Fetal distress & $8 / 22(36.4)$ & $8 / 29(27.6)$ & 1.00 \\
Delivery process block & $6 / 22(27.2)$ & $28 / 163(17.1)$ & 1.00 \\
Oxytocin use & $32 / 182(17.6)$ & $75 / 163(46.0)$ & 0.92 \\
Requirement of analgesia & $92 / 182(50.5)$ & $9 / 163(5.5)$ & 0.04 \\
Partus precipitatus & $5 / 182(2.7)$ & &
\end{tabular}

Data are mean \pm SD (range) or number (percentage) 
Table 4 Maternal morbidity

\begin{tabular}{llll}
\hline & Oral misoprostol $(n=212)$ & Dinoprostone $(n=199)$ & $p$ value \\
\hline Tachysystole & $15 / 212(7.0)$ & $19 / 199(9.5)$ & 0.61 \\
Hyperstimulation & $5 / 212(2.4)$ & $18 / 199(9.0)$ & 0.03 \\
Uterine hypertonus & $5 / 212(2.4)$ & $16 / 199(8.0)$ & 0.03 \\
Uterine rupture & $0 / 212$ & $0 / 199$ & \\
membrane rupture & $59 / 212(27.8)$ & $26 / 199(13.1)$ & 0.02 \\
Tocolytics & $6 / 212(2.8)$ & $17 / 199(8.5)$ & 0.04 \\
Postpartum heamorrhage $(\mathrm{ml})$ & $14 / 212(6.6)$ & $15 / 199(7.5)$ & 0.73 \\
$\quad \geq 500$ & $10 / 14(71.4)$ & $10 / 15(66.7)$ & \\
$\quad \geq 1000$ & $4 / 14(28.6)$ & $5 / 15(33.3)$ & 0.96 \\
Intravenous antibiotics & $32 / 212(15.1)$ & $35 / 199(17.6)$ & \\
Fever & 2 & 0 & \\
Shivering & 1 & 1 & \\
Nausea and vomiting & 2 & 1 & \\
\hline
\end{tabular}

Data are number (percentage)

Table 5 Neonatal outcomes

\begin{tabular}{llll}
\hline & Oral misoprostol $(n=212)$ & Dinoprostone $(n=199)$ & $p$ value \\
\hline Weight $(\mathrm{g})$ & $3020 \pm 566.5$ & $3110 \pm 499.3$ & 1.0 \\
Non-reassuring fetal heart rate & $15 / 212(7.1)$ & $22 / 199(11.1)$ & 0.04 \\
Meconium-stained liquor & $46 / 212(21.7)$ & $55 / 199(27.6)$ & 0.58 \\
Apgar score & & & \\
$\leq 7$ at 1 min & $8 / 212(3.8)$ & $9 / 199(4.5)$ & 0.66 \\
$\leq 7$ at 5 min & $3 / 212(1.4)$ & $3 / 199(1.5)$ & 1.0 \\
$\leq 7$ at 10 min & 0 & 1 & 1.0 \\
NICU admission & $15 / 212(7.0)$ & $15 / 199(7.5)$ & \\
Infant death & 0 & 0 & \\
\hline
\end{tabular}

Data are number (percentage)

reassuring fetal heart rate frequency in vaginal dinoprostone is obviously higher than OMS group $(p=0.04)$.

\section{Discussion}

Labor inductions have increased steadily over the past two decades, meanwhile many methods have been tested, but prostaglandins remain a preferred method for cervical ripening and labor induction [5, 6]. In 2001, Hofmeyr [7] compared the titrated oral misoprostol solution with vaginal dinoprostone for labor induction, proposed the new approach, titrated oral misoprostol solution administration and was successful in minimizing the risk of uterine hyperstimulation, and with no significant difference in maternal adverse effect and neonatal outcome between the two groups. From then on, many obstetricians pay attention to titrated oral misoprostol induction method because of its greater acceptance and fewer adverse effects. To further evaluate safety and efficacy of titrate oral misoprostol induction, many obstetricians compared with different labor induction method. Comparing OMS with conventional oxytocin induction, the result showed misoprostol was a safe and effective drug with low complications for the induction of labor, failure was seen less with misoprostol and cesarean sections are less frequently indicated as compared to oxytocin [8-10]. Comparing OMS with Foley catheter in cervical ripening and induction effect, OMS group showed higher rate of delivery in $24 \mathrm{~h}$, and in labor augmentation, cesarean section and instrumental delivery were somewhat fewer frequency than Foley group, but these differences were not statistically significant, side effects and neonatal complications were similar between the two groups [11]. A comparative study about oral and vaginal misoprostol for labor induction, which showed oral misoprostol was as effective as vaginal misoprostol with the advantage of shorter induction delivery interval, lower cesarean section rate, and lower incidence of failed 
induction rate, lower proportion of fetal distress and easy intake [12, 13]. In 2011, WHO guideline also strongly recommended oral misoprostol $(25 \mu \mathrm{g}, 2$-hourly) than vaginal low-dose misoprostol ( $25 \mu \mathrm{g}, 6$ hourly) for induction of labor. A randomized controlled trial about comparison of OMS with vaginal misoprostol showed that OMS associated with a lower incidence of uterine hyperstimulation and a lower cesarean delivery rate than vaginal misoprostol for labor induction in patients with unfavorable cervix [14]. A randomized double-blind trial compared efficacy and safety about OMS and oral misoprostol, participants were allocated to receive $20 \mathrm{ml}$ of misoprostol solution $(1 \mu \mathrm{g} / \mathrm{ml})$ orally every $1 \mathrm{~h}$ for four doses then titrated to $40 \mu \mathrm{g}$ every $1 \mathrm{~h}$ (OMS group) or $50 \mu \mathrm{g}$ of misoprostol orally every $4 \mathrm{~h}$ up to $12 \mathrm{~h}$ (oral group), and concluded that oral misoprostol was as effective as titrated misoprostol for cervical ripening and labor induction, but had a lower incidence of tachysystole and a lower total dose of misoprostol are required. Its results seem to be contradictory to previous studies, perhaps OMS dose and administration interval time difference could affect the outcomes of induction of labor [15]. A systematic review and net meta-analysis based on the data of Cochrane Pregnancy and Childbirth Group's Database of Trials show low dose $(<50 \mu \mathrm{g})$ titrated oral misoprostol solution had the lowest probability of cesarean section, whereas vaginal misprostol $(\geq 50 \mu \mathrm{g})$ had the highest probability of achieving a vaginal delivery within $24 \mathrm{~h}$ [6].

However, up to now, there are still no definite conclusions about the optimal dose, interval time and route of administration. In our study, we take the new method that gradually increase titrated oral misoprostol solution dose, and adminstrate by $1-2 \mathrm{~h}$, compare with vaginal dinoprotone for evaluating its effectiveness and safety. Evaluation from mode and outcomes of delivery, which is similar for total proportion of vaginal delivery between the two groups during $48 \mathrm{~h}$, nevertheless titrated oral misoprostol has the property of relatively slower duration of labor compared with dinoprostone, but accompanied the lower rate of uterine hyperstimulation, hypertonus, usage frequency of tocolytics and non-reassuring fetal heart; and concurrently OMS with lower incidence of tachysystole, cesarean delivery rate although with little significant difference in our study. Analyzed from the respect of neonatal outcomes, meconium-stained liquor rate in OMS group are lower than vaginal dinoprostone. From these points of view, titrated oral misoprostol is safer than dinoprostone for women labor induction, these results are as same as other studies.

The incidence of non-reassuring fetal heart rate in dinoprostone was significantly higher than OMS group, we also found that the rate of fetal distress in dinoprotone was also higher than OMS group, but the total proportion of cesarean section between two group showed no difference because of higher incidence of usage of tocolytics in dinoprostone. Uterine tachysystole, hyperstimulation, hypertonus accompanied non-reassuring fetal heart rate, tocolytics should be used to at once, so that a part of women would not been dealt with cesarean section. I think that may be the reason of our study with higher non-reassuring fetal heart rate rather without higher incidence of cesarean section in dinoprostone.

The phenomenon of higher proportion membrane rupture in oral misoprostol perplexed us, and we exclude the reason of amniotic membrane infection by placental histopathology. This phenomenon was not reported in other document literature, but 54 women in OMS group and 23 women in dinoprostone group presented on regular uterine contraction and delivered within $12 \mathrm{~h}$, and three women did not present regular uterine contraction after $12 \mathrm{~h}$, then experienced oxytocin induction and delivered, two women who presented delivery process block were transferred to cesarean section. We thought that higher incidence of membrane rupture in OMS group needed to be further studied by expanded sample size.

Based on the cervix Bishop score, we found that with the lower of cervix Bishop score, corresponding emergency needed higher dose of oral misoprostol solution and longer duration of time for labor induction. We consider that other procedure of labor induction with OMS will be studied, for women with lower Bishop score $\leq 3$, could be administrated higher dose of initial dose, and increased more than $10 \mu \mathrm{g}$ every time, and been longer than $2 \mathrm{~h}$ interval. Of course, optimum dose and interval of administration for women with low Bishop score need further extensive and intensive study.

In conclusion, titrated oral misoprostol given hourly for labor induction is as effective as vaginal dinoprostone from the respect of maternal/fetal outcomes, but titrated oral misoprostol is associated with lower rate of uterine hyperstimulation, hypertonus, tachysystole, and nonreassuring fetal heart compared with vaginal dinoprostone. Taking into account the higher vaginal delivery rate, lower adverse effect for maternal/fetal outcomes, costs and women's preferences; our study consider that titrated oral misoprostol solution would be a safe, cost-effective and patient favorite way for inducing labor.

\section{Compliance with ethical standards}

Conflict of interest The authors report no declarations of interest.

Open Access This article is distributed under the terms of the Creative Commons Attribution 4.0 International License (http://crea tivecommons.org/licenses/by/4.0/), which permits unrestricted use, distribution, and reproduction in any medium, provided you give appropriate credit to the original author(s) and the source, provide a link to the Creative Commons license, and indicate if changes were made. 


\section{References}

1. Geeta K, Swamy MD (2012) Current methods of labor induction. Semin Perinatol 36(5):348-352

2. ACOG Committee on Practice (2009) Bulletins-obstetrics. ACOG practice bulletin no. 107. Induction of labor. Obstet Gynecol 114(3):86-97

3. Gulmezoglu AM, Crowther CA, Middleton P, Heatley E (2012) Induction of labour for improving birth outcomes for women at or beyond term. Cochrane Database Syst Rev. doi:10.1002/ 14651858.CD004945.pub3

4. Tang J, Kapp N, Dragoman M, de Souza JP (2013) WHO recommendations for misoprostol use for obstetric and gynecologic indications. Int J Gynaecol Obstet 121:186-189

5. Aghideh FK, Mullin PM, Ingles S, Ouzounian JG, Opper N, Wilson ML, Miller DA, Lee RH (2014) A comparison of obstetrical outcomes with labor induction agents used at term. J Matern Fetal Neonatal Med 27(6):592-596

6. Alfirevic Z, Keeney E, Dowswell T, Welton NJ, Dias S, Jones LV, Navaratnam K, Caldwell DM (2015) Labor induction with prostaglandins: a systematic review and network meta-analysis. BMJ 5(350):h217

7. Hofmeyr GJ, Alfirevic Z, Matonhodze B, Brocklehurst $P$, Campbell E, Nikodem VC (2001) Titrated oral misoprostol solution for induction of labour: a multi-centre, randomised trial. BJOG 108(9):952-959

8. Aalami-Harandi R, Karamalim M, Moeini A (2013) Induction of labor with titrated oral misoprostol solution versus oxytocin in term pregnancy: randomized controlled trial. Rev Bras Ginecol Obstet 35(2):60-65
9. Bleich AT, Villano KS, Lo JY, Alexander JM, McIntire DD, Leveno KJ (2011) Oral misoprostol for labor augmentation: a randomized controlled trial. Obstet Gynecol 118(6): $1255-1260$

10. Vogel JP, West HM, Dowswell T (2013) Titrated oral misoprostol for augmenting labor to improve maternal and neonatal outcomes. Cochrane Database Syst Rev 23(9):CD010648

11. Ten Eikelder ML, Neervoort F, Oude Rengerink K, van Baaren GJ, Jozwiak M, de Leeuw JW et al (2013) Induction of labour with a Foley catheter or oral misoprostol at term: the PROBAATII study, a multicentre randomised controlled trial. BMC Pregnancy Childbirth 13:67

12. Souza AS, Feitosa FE, Costa AA, Pereira AP, Carvalho AS, Paixão RM et al (2013) Titrated oral misoprostol solution versus vaginal misoprostol for labor induction. Int J Gynaecol Obstet 123(3):207-212

13. Amporn T, Kusol R, Prapat W, Buraya P, Alita C (2012) Comparison of the efficacy and safety of titrated oral misoprostol and a conventional oral regimen for cervical ripening and labor induction. Int J Gynaecol Obstet 116(1):13-16

14. Faucett AM, Daniels K, Lee HC, El-Sayed YY, Blumenfeld YJ (2014) Oral misoprostol versus vaginal dinoprostone for labor induction in nulliparous women at term. J Perinatol 34(2):95-99

15. Thaisomboon A, Russameecharoen K, Wanitpongpan P, Phattanachindakun B, Changnoi A (2012) Comparison of the efficacy and safety of titrated oral misoprostol and a conventional oral regimen for cervical ripening and labor induction. Int J Gynaecol Obstet 116(1):13-16 